\title{
TRANSFORMASI SOSIAL-POLITIK MASA AWAL KERAJAAN NEPO: KAJIAN BERDASARKAN SUMBER NASKAH LONTARA DAN DATA ARKEOLOGI
}

\author{
Transformation of the Social-Political in Early Nepo Kingdom: \\ Study Based on Lontara Script and Archaeological Data
}

\author{
Makmur \\ Balai Arkeologi Sulawesi Selatan \\ Jl. Pajjaiyang No. 13 Sudiang Raya Makassar, Indonesia \\ makmurdpmks@gmail.com
}

Naskah diterima: 31/08/2017; direvisi: 11/10-30/11/2017; disetujui: 30/11/2017

Publikasi ejurnal: 12/12/2017

\begin{abstract}
This research is intended to improve the traces of the Nepo Kingdom located in Barru District of South Sulawesi Province, focusing on the early studies of Nepo Kingdom when in lead by Arung Pattapulo (forty kings) to the government of La Bongngo. The first research method used, the literature study which is the source of the Nepo lontara manuscript and Manuba Lontara, the result of lontara manuscript reading is used as the initial guidance to attract toponim or places in the lontara script. The second method is direct observation of spaciousness for recording artefacts and features and performs recording of collective memory data of society (speech tradition) concept of society related to the early days of Nepo Kingdom until the reign of Arung La Bongngo, Nepo Kingdom governance system, transformation of settlement and agriculture in the early days of Nepo Kingdom.

Keywords: Transformation, Nepo Kingdom, Lontara, Artifacts and Features.
\end{abstract}

\begin{abstract}
Abstrak
Penelitian ini bertujuan untuk menelusuri jejak Kerajaan Nepo yang berada di Kabupaten Barru Propinsi Sulawesi Selatan, fokus kajiannya ialah masa awal Kerajaan Nepo pada saat dipimpin oleh Arung Pattapulo (empat puluh raja) sampai pemerintahan Arung La Bongngo. Metode penelitian yang digunakan ialah pertama, studi literatur yang sumber dari naskah Lontara Nepo dan Lontara Manuba, hasil pembacaan naskah lontara dijadikan petunjuk awal untuk menelusuri topoinim atau tempat-tempat yang disebutkan dalam naskah Lontara Nepo. Metode yang kedua yaitu observasi langsung ke lapangan untuk merekam artefak dan fitur serta melakukan perekaman data ingatan kolektif masyarakat (tradisi tutur) berupa wawancara masyarakat yang berkaitan dengan masa-masa awal terbentuknya Kerajaan Nepo hingga masa pemerintahan Arung La Bongngo, sehingga mendapatkan gambaran proses transformasi kepemimpinan, sistem tata kelola Kerajaan Nepo, transformasi pemukiman dan pertanian pada masa awal Kerajaan Nepo.
\end{abstract}

Kata Kunci: Transformasi, Kerajaan Nepo, Lontara, Artefak dan Fitur.

\section{PENDAHULUAN}

Pada akhir milenium pertama masehi, kerajaan Bugis dan Makassar telah menjalin konektifitas dengan berbagai masyarakat yang berada di luar Pulau Sulawesi. Hal tersebut didorong oleh intensifikasi perdagangan, perkembangan dibidang ekonomi, sosial, dan politik di Pulau Sulawesi. Sehingga masyarakat yang mendiami Pulau Sulawesi Selatan telah masuk ke dalam jaringan perdagangan dunia, hal itu dapat kita lihat dari temuan keramik Cina dari abad ke-10 di berbagai situs di Sulawesi Selatan (Pelras, 2006: 5354).

Pada masa selanjutnya yaitu abad ke14 hingga abad ke-16 terjadi perubahan kehidupan sosial, politik, ekonomi di kawasan Sulawesi Selatan. Ditandai dengan pesatnya pertumbuhan penduduk, 
perkembangan teknologi budidaya padi dan perluasan wilayah berbagai kerajaan, diikuti dengan pembukaan lahan pertanian secara besar-besaran serta banyaknya pembangunan pemukiman baru. Proses perubahan tidak selalu berjalan mulus, banyak diwarnai dengan konflik kepentingan dan persaingan antar berbagai kerajaan. Akibat dari perubahan sosial politik lahirlah sistem kerajaan utama dan kerajaan bawahan yang didasarkan atas hubungan perjanjian (Zid dkk, 2009: 39).

Pada umumnya kerajaan-kerajaan di Sulawesi Selatan bermula dari keberadaan Tomanurung, berbeda halnya dengan Kerajaan Nepo di Kabupaten Barru Propinsi Sulawesi Selatan. Awal terbentuknya Kerajaan Nepo dimulai dari keberadaan Arung Pattapulo (empat puluh raja). Para Arung mempunyai daerah otonom dalam pelaksanaan pemerintahan dalam konteks wilayah teritori dan pengelolaan sumber daya alam. Penelusuran sejarah Kerajaan Nepo telah banyak diungkap dalam buku berjudul Kerajaan Nepo ditulis oleh A. Rasyid Asba (2010). Buku tersebut mengulas tentang peristiwa masa-masa awal eksistensi Kerajaan Nepo dipimpin oleh empat puluh raja (Arung Pattapulo) yang secara bersamaan, baik dalam aspek kedudukan maupun dalam aspek kekuasaan yang sama. Dalam buku tersebut juga dibahas tentang raja-raja yang memimpin Kerajaan Nepo, mulai dari Arung La Bongngo putra dari Datu Suppa' yang diangkat untuk menjadi pemimpin di Kerajaan Nepo atas dasar permintaan Arung Pattapulo, sampai kepemimpinan Arung La Calo (Asba, 2010: 37).

Buku tersebut lebih banyak memperbincangkan tentang periodisasi antara satu raja dengan raja yang lain dalam memimpin Kerajaan Nepo. Belum melihat bagaimana pilihan-pilihan politik para Arung Pattapulo pada masa awal Kerajaan Nepo. Seperti penguasaan lahan-lahan subur untuk menjaga keberlangsungan masyarakat mereka yang sering berujung konflik diantara mereka. Serta bagaimana para Arung Pattapulo dalam menghadapi kontestasi antar kerajaan khususnya dalam wilayah regional pesisir barat yang pada saat itu dikuasai oleh Kerajaan Suppa' dan bagaimana Arung La Bonggo bersama para Arung Pattapulo membangun kerajaan Nepo melalui sumber daya alam yang dimiliki. Sehingga pertanyaan penelitian yang ingin dijawab ialah bagaimana transformasi sosial-politik Kerajaan Nepo pada masa awal?

Menurut Antoniades, transformasi adalah sebuah proses perubahan bentuk secara berangsur-angsur, sehingga sampai pada tahap akhir, perubahan dilakukan dengan cara memberikan respon terhadap pengaruh perubahan unsur eksternal dan internal (Bukit dkk, 2012:53). Transformasi selalu menyangkut perubahan masyarakat dari satu masyarakat yang lebih sederhana ke masyarakat yang lebih modern (Zaeny, 2005:156). Perubahan sosial selalu berkaitan dengan perubahan nilai-nilai sosial, pola perilaku, organisasi, lembaga kemasyarakatan, lapisan dalam masyarakat, kekuasaan dan kewenangan (Syani, 1995: 83-84).

Berdasarkan permasalahan yang telah dikemukakan di atas, maka penelitian ini bertujuan untuk memberikan gambaran tentang proses transformasi sosial politik Kerajaan Nepo, menuju kedamaian dan kesejahteraan di masa kepemimpinan Arung La Bongngo. Agar dapat memberikan gambaran corak kebudayaan masyarakat Nepo berdasarkan temuan arkeologis.

\section{METODE PENELITIAN}

Penelitian tentang Kerajan Nepo yang ada di Kecamatan Mallusetasi Kabupaten Barru Propinsi Sulawesi Selatan dilaksanakan pada tahun 2014. Penelitian ini berupaya melakukan penelusuran terhadap data arkeologi berkaitan dengan Kerajaan Nepo pada masa awal terbentuknya, guna mengetahui proses transformasi Kerajaan Nepo. Jenis penelitian ini adalah penelitian 
kualitatif yaitu mendeskripsikan atau memberikan gambaran terhadap tempat bersejarah baik dalam aspek keletakan, bentuk maupun temuan-temuan berupa artefak dan fitur.

Metode pengumpulan data dengan cara studi pustaka baik bersumber dari bukubuku yang telah diterbitkan maupun dari sumber naskah lontara Nepo dan lontara Manuba, dari hasil pembacaan naskah lontara dijadikan petunjuk awal untuk menelusuri toponim atau tempat-tempat yang disebutkan dalam naskah lontara. Kemudian melakukan observasi langsung kelapangan dengan teknik survei permukaan tanah, kegiatan ini dilakukan dengan cara mengamati permukaan tanah dengan jarak dekat, pengamatan tersebut untuk mendapatkan data arkeologi dalam konteksnya dan lingkungan sekitarnya (Simanjuntak dkk, 2008: 22). Serta melakukan perekaman data ingatan kolektif masyarakat (tradisi tutur) berupa wawancara masyarakat terkait dengan Kerajaan Nepo. Analisis yang digunakan yaitu analisis morfologi, teknologi dan kontekstual terhadap artefak yang ditemukan baik dari segi keanekaragaman jenis, bentuk serta fungsinya. Cerita-cerita dalam naskah Lontara Nepo dan Lontara Manuba khususnya tempat-tempat yang disebutkan dilakukan pengecekan lapangan.

\section{HASIL DAN PEMBAHASAN}

\section{Transformasi Kepemimpinan}

Berbagai sumber tertulis telah banyak memberikan informasi bahwa masa awal terbentuknya Kerajaan Nepo dipimpin oleh empat puluh raja (Arung Pattapulo). Begitu juga ingatan kolektif masyarakat setempat juga menceritakan hal yang sama. Seperti dalam naskah lontara Nepo milik Yusuf H.A, disebutkan bahwa :

"Dahulu di Nepo ada empat puluh 40 arung, mereka bersama-bersama mengatur jalannya pemerintahan di Nepo. Mereka yang masih dicatat namanya dalam lontara ialah Arung Talabangi, Arung Pacciro, Arung Tagulici, Arung Pabiungeng,
Arung Latunreng, Arung Langélo, Arung Masiku, Arung Ngonynyi, Arung Marowanging, Arung Dusu, Arung Atapang, dan lainnya" (Lontara Nepo Page 198, Terj. Hadrawi, 2014).

Dalam proses kepemimpinan oleh empat puluh raja sangat sulit untuk mengambil suatu keputusan menyangkut mereka. Karena kepentingan antara satu raja dengan raja yang lain berbeda-beda, bahkan sering berujung perang saudara antara satu kelompok dengan kelompok lain karena perbedaan pandangan atau satu kelompok ingin menguasai kelompok yang lain. Hal itulah yang kemudian mendorong berbagai raja bermusyawarah untuk membicarakan fenomena sosial tersebut. Maka munculah inisiatif dari beberapa arung untuk mencari pemimpin untuk mereka, seperti di dalam naskah lontara Nepo milik Yusuf H.A, disebutkan:

"Dua tiga dari Arung Patappulo kemudian berani mengangkat bicara dengan berkata: "Ada baiknya apabila kita membuat kesepakatan untuk mencari seseorang yang menjadi Arung untuk memimpin kita sesama Arung Patappulo. Namun, janganlah Arung Talabangi statusnya sama saja dengan kita”.

"Akhirnya pertemuan itu orang Nepo melahirkan kesepakatan bersama, Arung Patappulo akan berangkat ke Suppa' untuk berjumpa dengan Datu Suppa'. Mereka sepakat akan meminta seorang turunan bangsawan Suppa' untuk mengangkatnya sebagai raja di Népo. Raja itu kemudian akan dijadikan sebagai pemimpin para Arung Patappulo. Meskipun demikian, kekuasaan tetap berada pada diri para Arung Patappulo secara bersama-sama. Raja Nepo hanya menjadi pemimpin para Arung Patappulo" (Lontara Nepo Page 199, Terj. Hadrawi, 2014).

Setelah mereka bertemu dengan Datu Suppa', mereka meminta keturunan dari Datu Suppa' untuk menjadi raja di Nepo dan Datu Suppa' menyetujui permintaan empat puluh raja Nepo, maka ditunjuklah anaknya yang belum mempunyai jabatan atau kedudukan yaitu La Bongngo. Meski La Bongngo adalah orang bodoh dan tidak 
mempunyai harta akan tetapi empat puluh raja siap menerima konsekuensi tersebut dan akan membuat La Bongngo menjadi pintar dan berharta. Datu Suppa' pun berucap :

"Datu Suppa' La Teddulloppo menyambut ucapan Hadat Népo dan berkata: "Wahai, Népo! Tinggi pengharapanmu pada anak kita, justru itu tinggi pula rasa kesyukuranku atas harapanmu pada diri saya. Semoga Tuhan memberi kalian kepuasan dalam mencari pemimpin. Kami senang karena hambalah yang mencari tuan. Engkau mengatakan bahwa engkau menelusuri turunan bangsawan Tomanurung yang dihormati untuk memerintah di Népo. Oleh karena itu, saya berucap kepada kalian para pamanku serta para saudaraku di Népo bahwa, orang yang dapat menjaga kalian agar tidak hampa dan menyelimuti agar tidak kedinginan adalah orang yang diberi petunjuk oleh Dewata Yang Esa serta memiliki empat kekuatan sempurna" (Lontara Nepo Page 201, Terj. Hadrawi, 2014).

Di situlah awal proses transformasi dari kepemimpinan kolektif (empat puluh raja) menjadi kepemimpinan yang tunggal yang dipimpin oleh Arung La Bongngo. Permintaan Arung Pattapulo kepada Datu Suppa' Teddung Lompoe bukan hanya pertimbangan keturunan raja, tetapi juga pertimbangan keamanan dan jalur perdagangan. Karena pada masa itu Kerajaan Suppa' punya pengaruh besar di wilayah pesisir barat pulau Sulawesi Selatan.

Permintaan Empat puluh raja Nepo ke Datu Suppa', agar keturunannya menjadi raja di Nepo merupakan hubungan simbiosis mutualisme, dimana dua pelah pihak samasama saling menguntungkan. Pihak Kerajaan Suppa' mendapatkan keuntungan memperluas wilayah kekuasaan sehingga Kerajaan Nepo merupakan Palili Passajinge (kerajaan bagian yang didasarkan oleh hubungan kekeluargaan), Kerajaan Nepo berkewajiban memberikan upeti sebesar 4 real (Lontara Manuba). Sedangkan keuntungan bagi Kerajaan Nepo adalah mendapatkan perlindungan oleh Kerajaan
Suppa', dimana pada masa itu Kerajaan Suppa' merupakan kerajaan terbesar di pesisir barat Sulawesi Selatan. Kerajaan Suppa' juga pada masa itu sudah punya kontak dagang dengan pihak-pihak luar, sehingga mempermudah bagi Kerajaan Nepo untuk memasarkan produk-produk hasil pertanian mereka. Selain keuntungan ekonomi, Kerajaan Nepo terhindar dari perang saudara antar empat puluh raja (Arung Pattapulo).

\section{Transformasi Sistem Kerajaan Nepo}

Pada masa kekuasaan empat pulu raja (Arung Pattapulo) tidak ada sistem yang hirarkis yang mengikat antara para raja (arung). Proses interaksi antara mereka menggunakan hukum rimba, dimana yang paling kuat akan menguasi pihak yang lemah. Hal itu juga tercermin dalam penguasaan lahan-lahan subur, dimana yang kuat menempati lahan-lahan subur sedangkan yang lemah tersingkir ke tempattempat tidak subur. Reposisi antara satu kelompok dengan kelompok lain kerap terjadi. Seperti di dalam naskah lontara Nepo milik Yusuf H.A disebutkan :

"Negeri Nepo terbagi dalam empat puluh kampung. Mereka bersaudara dan bersepupu. Bagi yang kuat, tinggal di tanah datar atau tanah hamparan pertanian. Tetapi kampung yang lemah memilih tempat di gunung. Ada pula yang tinggal di tepi aliran sungai, dan ada juga yang tinggal di hutanhutan" (Lontara Nepo Page 198, Terj. Hadrawi, 2014).

Pola kehidupan sosial bermasyarakat seperti itu, telah menimbulkan kesenjangan sosial yang tinggi, dimana kelompok yang kuat menguasai lahan subur dan pada akhirnya lebih sejahtera, sedangkan kelompok lemah hidup di lahan kurang subur dan akan termarjinalkan secara sosial ekonomi (Jones, 2010:156).

Setelah terjadi transformasi kepemimpinan di Kerajaan Nepo, dimana sudah ada pemimpin tunggal, maka pada saat itu pula akhir dari hukum rimba di 
Kerajaan Nepo. Untuk menjalankan roda pemerintahan, Arung La Bongngo juga membentuk struktur kerajaan untuk menjalankan pemerintahan, seperti di dalam naskah lontara Nepo milik Yusuf H.A, disebutkan:

La Bongngo Membentuk Jabatan/ Dewan

Adat Kerajaan Nepo

Dibentuk pula satu Sulewatang serta dua

Pabbicara.

Sulewatang bertugas sebagai perwakilan raja dan mendidik para anak arung Népo. Pabbicara adalah pejabat yang bertugas menyelesaikan masalah-masalah perkara hukum. Matowa adalah orang yang mengatur pejabat-pejabat istana kerajaan.

Sedangkan La Tima, La Tinrang, dan La Pettupiyona, adalah orang-orang yang menjabat sebagai Dewan Adat Népo dan mereka pulalah yang menjaga kemuliaan serta martabat hukum kerajaan Népo (Lontara Nepo Page 202, Terj. Hadrawi, 2014).

Narasi dalam naskah tersebut di atas memperlihatkan bahwa struktur Kerajaan Nepo sudah baik, dimana Arung La Bongngo telah dibantu oleh Salewatang, Pabbicara, Matoa dan Dewan Adat dalam menjalankan pemerintahan. Naskah tersebut juga menggambarkan kompleksitas kehidupan di Kerajaan Nepo sudah sangat nampak. Dimana sudah ada perwakilan raja ketika raja tidak bisa menghadiri sebuah acara dan ada juga orang yang bertugas untuk meningkatkan Sumber Daya Manusia (SDM) para arung yang ada di Nepo. Lembaga yudikatif yang bertugas menegakkan supremasi hukum, begitu pula sudah ada orang bertugas mengatur pejabat kerajaan. Selain fungsi-fungsi eksekutif juga sudah ada fungsi penyeimbang (legislatif) pemerintahan, yang bertugas untuk menjaga kemuliaan serta martabat hukum Kerajaan Nepo.

Perubahan sistem kepemimpinan sesungguhnya tidak mengubah ciri khas Kerajaan Nepo sebagai kerajaan konfederasi yang dibentuk oleh para Arung Pattapulo, karena dalam menjalankan pemerintahan sepenuhnya dilakukan oleh para Arung Pattapulo yang diposisikan ke dalam struktur kerajaan seperti Salewatang, Pabbicara, Matoa dan Dewan Adat. Bentukbentuk penyatuan beberapa kerajaan sangat umum dilakukan di Sulawesi Selatan seperti konfenderasi Ajatappareng yang didalamnya tergabung Sidenreng, Rapang, Suppa, Sawitto dan Alitta yang diperkirakan awal terbentuknya pada abad ke-15 (Muheminah dan Makmur, 2015:134). Persekutuan kampung atau wanuwa dapat kita lihat di daerah Soppeng, enam puluh wanuwa yang dipimpin oleh matowa di setiap wanua. Mereka berhasil mengangkat raja yaitu Tomanurung La Temamala dan posisi enam puluh matowa (Matowa Ennappulona) sebagai dewan adat Kerajaan/Kedatuan Soppeng (Makmur dan Hadrawi, 2016:167).

Perubahan kepemimpinan di Kerajaan Nepo berakibat adanya pusat kekuasaan yaitu kerajaan, jejak Kerajaan Nepo terdapat di Desa Nepo Kecamatan Mallusetasi Kabupaten Barru. Menurut masyarakat lokal, bahwa bekas istana Kerajaan Nepo ada 2 (dua) yaitu:

\section{a. Bekas Istana Kerajaan Nepo}

Letak bekas Istana Kerajaan Nepo berada di sisi kiri jalan poros desa, tepatnya di depan kompleks pemakaman yang ada di Desa Nepo dengan posisi astronomi lintang selatan $04^{\circ} 11^{\prime} 30.7^{\prime}$ ' bujur timur $119^{\circ} 40^{\prime}$ 28.3" dengan ketinggian 27 MDPL. Tinggalan arkeologi yang ditemukan dilokasi ini berupa sebaran fragmen gerabah dan fragmen keramik. Lokasi istana Kerajaan Nepo kini sudah menjadi area persawahan masyarakat.

Temuan fragmen keramik didominasi oleh keramik Qing (abad 17-18) yaitu sebanyak 19 buah, kemudian keramik Eropa (abad 18-19) sebanyak 9 buah dan Keramik yang lebih tua yaitu sawankhalok (abad 16) sebanyak 1 buah, begitu pula ditemukan fregmen gerabah sebanyak 39 buah (Muhaeminah dkk, 2014:57). 


\section{b. Bekas Istana Kerajaan Nepo (kini di depan Nepo)}

Menurut informasi masyarakat bahwa istana Kerajaan Nepo pernah dipindahkan ke sebelah barat, sekitar 100 meter dari lokasi istana yang pertama, tepatnya di depan masjid di Desa Nepo, dengan posisi astronomi lintang selatan $04^{\circ}$ 11 ' 36.8" bujur timur $119^{\circ} 40^{\prime} 28.8^{\prime}$ " dengan ketinggian 28 MDPL. Lokasi ini sekarang sudah menjadi rumah salah satu masyarakat. Namun jejak-jejak arkeologi masih bisa ditemukan berupa fragmen keramik Qing (abad 17-18) sebanyak 19 buah, keramik Ming (abad 16-17) sebanyak 1 buah dan 1 (satu) buah mata uang Belanda (Muhaeminah dkk, 2014:57).

Hasil identifikasi keramik menunjuk bahwa kronologi di bekas istana Kerajaan Nepo yang paling tua berasal dari abad ke16, meski jumlahnya tidak representatif dibandingkan dengan abad selanjutnya. Kemungkinan pada abad ke 16, merupakan awal kontak para arung di Nepo dengan masyarakat luar, sementara keramik periode selanjutnya yaitu abad ke 17-18 merupakan puncak kejayaan Kerajaan Nepo, kemudian pada abad ke 18-19 mengalami penurunan.

\section{Transformasi Pemukiman Arung Nepo \\ Pemukiman para Arung Pattapulo} (empat puluh raja) di Nepo kerap kali berpindah, karena kalah dengan arung yang lebih kuat, mereka berpindah ke gununggunung ada pula berpindah ke lereng-lereng. Setelah terjadi transformasi kepemimpinan dan sistem kerajaan, semua wilayah telah dibagi-bagi dan sifatnya sudah tetap, sehingga setiap arung mempunyai satu wilayah kekuasaan. Adapun pemukimanpemukiman arung yang masih bisa ditemukan hingga saat ini adalah:

\section{a. Pemukiman Arung Mareppang}

Situs Mareppang berada diwilayah Dusun Mareppang Desa Nepo Kecamatan Mallusetasi dengan posisi astronomi lintang selatan $04^{\circ} 10^{\prime} 30.4^{\prime \prime}$ bujur timur $119^{\circ} 40^{\prime}$ 06.1" dengan ketinggian 41 MDPL, lokasi ini berada di pinggir sungai yang cukup besar. Situs Masreppang adalah bekas pemukiman Arung Mareppang, lokasi ini telah berubah menjadi area persawahan masyarakat, sebaran fragmen gerabah dan fragmen keramik cukup padat ditemukan di dalam area persawahan. Sampel data yang diambil adalah fragmen keramik dinasti Ming $B w$ (abad 16-17) 3 buah, fragmen keramik dinasti Swatow (abad ke 17) 2 buah, fragmen keramik dinasti Qing (abad ke 17-18) 8 buah, fragmen keramik dinasti Qing Muda (abad ke 20) 4 buah, fragmen keramik Vietnam (abad 15-16) 2 buah, fragmen keramik Eropa (abad 18-19) 9 buah, dan fragmen gerabah 32 buah (Muhaeminah dkk, 2014:57). Temuan lain berupa struktur pondasi bekas masjid yang terbuat dari susunan batu andesit dan sudah dieratkan dengan semen.

\section{b. Pemukiman Arung Topporeng}

Situs Topporeng terletak di pinggir jalan Desa Nepo, tepatnya berada di samping SLTP. Secara administrasi Situs Topporeng berada di wilayah Dusun Topporeng Desa Nepo Kecamatan Mallusetasi dengan posisi astronomi lintang selatan $04^{\circ} 11^{\prime} 09.6^{\prime}$ "bujur timur $119^{\circ} 39^{\prime} 24.5^{\prime}$ ' dengan ketinggian 27 MDPL. Bekas pemukiman Arung Topporeng sudah berubah menjadi salah satu rumah yang dimiliki oleh masyarakat setempat. Temuan arkeologis berupa fragmen keramik dan gerabah cukup padat dan tersebar di wilayah tersebut. Berikut ini data fragmen keramik dinasti Qing (abad ke 17-18) 4 buah, fragmen keramik Stoneware (abad 17-18) 1 buah, fragmen keramik Eropa (abad ke 18-19) 4 buah, dan fragmen gerabah 26 buah (Muhaeminah dkk, 2014:57).

\section{c. Pemukiman Arung Mario Rio}

Situs Mario Rio berada dalam wilayah administrasi Dusun Mario Rio Desa Nepo Kecamatan Mallusetasi dengan posisi 
astronomi lintang selatan $04^{\circ} 10^{\prime} 40.3$ " bujur timur $119^{\circ} 39^{\prime} 15.1^{\prime \prime}$ dengan ketinggian 28 MDPL. Bekas pemukiman Arung Mario Rio kini tinggal sebidang tanah tanpa ada bangunan, di dalamnya banyak ditumbuhi oleh tanaman pisang dan pohon-pohon besar. Pada area tersebut terdapat dua buah lesung batu yang memiliki jejak pakai yang cukup halus pada lubang lesung batu. Sebaran fragmen keramik dinasti Ming $B w$ (abad ke 16) 1 buah, fragmen keramik dinasti Qing (abad 17-18) 17 buah, fragmen keramik Swatow (abad 17) 5 buah, fragmen keramik Vietnam (abad 16) 1 buah, fragmen keramik Eropa (abad 18-19) 34 buah, fragmen keramik Stoneware (abad ke-19) Cina 3 buah, dan fragmen gerabah 38 buah (Muhaeminah dkk, 2014:57).

\section{d. Pemukiman Arung Cengkenge}

Situs Cengkenge berdekatan dengan sawah Lapetupiona dan Situs Atapang yang berada di Desa Batu Putih Kecamatan Mallusetasi dengan posisi astronomi lintang selatan $04^{\circ} 12^{\prime} 20.0^{\prime \prime}$ bujur timur $119^{\circ} 38^{\prime}$ 30.4" dengan ketinggian 19 MDPL. Bekas Soraja atau rumah Arung Cengkenge berada di bukit-bukit kecil yang disampingnya terdapat sungai. Area ini dipenuhi oleh tumbuhan-tumbuhan liar, akan tetapi masih ada fragmen gerabah dan fragmen keramik di dalam area tersebut yang dapat ditemukan. Temuan fragmen keramik dinasti Qing (abad 17-18) 3 buah, fragmen keramik Eropa (abad 18-19) 3 buah, dan fragmen gerabah 13 buah (Muhaeminah dkk, 2014:57).

\section{e. Pemukiman Arung Lapao}

Situs Lapao berada di Dusun Lapao Desa Manuba Kecamatan Mallusetasi dengan posisi astronomi lintang selatan $04^{\circ}$ 12' 50.3" bujur timur $119^{\circ} 39^{\prime} 04.2^{\prime}$ " dengan ketinggian 12 MDPL. Situs ini merupakan bekas pemukiman Arung Lapao yang kini hanya tinggal sebidang tanah yang dimanfaatkan oleh masyarakat untuk menanam pohon pisang. Tinggalan arkeologi yang ada dipermukaan tanah hanya dua buah fragmen tembikar disebabkan daerah ini sering mengalami banjir hingga ketinggian $\pm 1 \mathrm{M}$ ( Muhaeminah dkk, 2014:57).

Sebaran fragmen keramik dan fragmen gerabah dipemukiman para arung di Nepo cukup padat. Fragmen keramik yang ditemukan cukup beragam mulai dari keramik kronologi tertua berasal dari Vietnam abad 16, keramik Sawankhalok abad 16, keramik dinasti Ming abad 16-17, keramik dinasti Qing abad 17-18, keramik Swatow abad 17, keramik Eropa abad 18-19, keramik Stoneware Cina abad 18-19. Frekwensi temuan yang paling banyak ditemukan di pemukiman Arung Mario Rio sebanyak 61 buah fragmen keramik. Di pemukiman Arung Mareppang sebanyak 28 buah fragmen keramik, selanjutnya pemukiman Topporeng sebanyak 12 buah fragmen keramik, dan yang paling sedikit di pemukiman Cengkeng sebanyak 6 buah fragmen keramik. Hal ini menandakan bahwa pemukiman Arung Mario Rio merupakan pemukiman yang paling tinggi nilai strategisnya dibandingkan dengan pemukiman para arung yang lain. Di pemukiman Arung Mario Rio ditemukan lesung 2 buah yang jejak pakainya cukup halus.

Hasil identifikasi keramik menunjukkan bahwa kronologi relatif di wilayah pemukiman para arung di Nepo. Fragmen keramik paling tua berasal dari abad ke-16, meski jumlahnya tidak banyak dibandingkan dengan abad selanjutnya. Sementara keramik periode selanjutnya yaitu abad ke 17-18, dimana fase ini merupakan fase perkembangan pemukiman para arung di Nepo. Puncak perkembangan pemukiman para arung di Nepo berada pada abad ke 18-19, dimana pada saat periode yang sama pusat Kerajaan Nepo mengalami kemunduran.

Keberadaan temuan keramik di wilayah pemukiman para arung di Nepo berhubungan erat dengan proses perniagaan, 


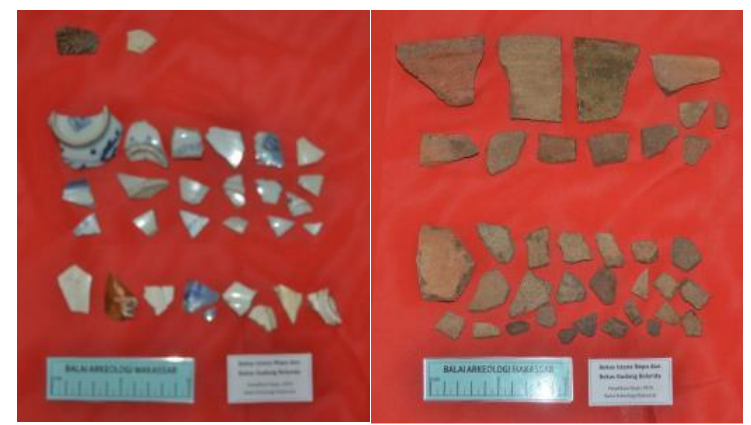

Gambar 1. Fragmen keramik (kiri) dan gerabah (kanan) di bekas Istana Kerajaan Nepo

(Sumber: Dok. Balai Arkeologi Makassar, Tahun 2014)

karena keramik merupakan barang yang diperdagangkan pada masa tersebut. Sedangkan temuan fragmen gerabah di identifikasi sebagai kendi dan tempayan. Sementara temuan dua buah lesung batu di pemukiman Arung Mario Rio yang dipergunakan untuk menumbuk biji-bijian dari hasil pertanian, hal itu menandakan bahwa corak kebudayaan masyarakat Nepo merupakan masyarakat agraris. Sementara temuan struktur pondasi masjid di pemukiman Arung Mareppang masih baru karena sudah memakai bahan semen, ini diperkirakan dibuat pada abad ke 19-20 karena pada masa tersebut Islam sudah menyebar luar hingga ke pelosok Sulawesi.

\section{Corak Kebudayaan Agraris Masyarakat Nepo}

Pemerintahan Arung La Bongngo di Kerajaan Nepo, telah merubah total sistem pertanian, dari pertanian ladang di bukitbukit diubah menjadi pertanian sawah pada dataran rendah. Hal itu bisa terlihat adanya sekelompok orang yang diduga berasal dari suku Makassar, mereka meminta perlindungan dan tempat tinggal di Kerajaan Nepo. Sekelompok orang tersebut dinamakan orang Pakkang, oleh Arung La Bongngo orang-orang tersebut diberikan tempat tinggal dan izin untuk membuka area persawahan, sawah tersebut kemudian dinamakan sawah Diapung. Sawah Diapung masih bisa ditemukan, kini berada di wilayah administrasi Kelurahan Mallawa
Kecamatan Mallusetasi dengan posisi astronomi lintang selatan $04^{\circ} 10^{\prime} 46.3^{\prime \prime}$ bujur timur $119^{\circ} 38^{\prime} 43.7^{\prime \prime}$ dengan ketinggian 23 MDPL. Aktifitas keseharian orang-orang Pakkang telah meresahkan masyarakat setempat. Banyak melakukan perampokan terhadap masyarakat yang melintas di daerah tersebut, akibat ulahnya pihak Kerajaan Nepo memindahkan orang-orang Pakkang ke daerah Atapang, dan sawah Diapung diambil alih oleh pihak Kerajaan Nepo.

Setelah orang-orang Pakkang bermukim di daerah Atapang, pihak Kerajaan Nepo kembali memberikan izin untuk membuka area persawahan. Orangorang Pakkang berhasil membuka area persawahan, yang kemudian diberikan nama sawah Lapetupiona. Area persawahan tersebut masih bisa ditemukan, yaitu berada di wilayah administrasi Desa Batu Putih Kecamatan Mallusetasi dengan posisi astronomi lintang selatan $04^{\circ} 12^{\prime} 17.2^{\prime \prime}$ bujur timur $119^{\circ} 38^{\prime} 31.5^{\prime}$ " dengan ketinggian 16 MDPL. Kebiasaan orang-orang Pakkang melakukan perampokan terhadap masyarakat setempat masih dilakukan dan pihak Kerajaan Nepo kembali memindahkan mereka ke wilayah Congko, sedangkan sawah yang telah mereka buat diambil alih oleh pihak Kerajaan Nepo.

Pada saat orang-orang Pakkang bermukim di wilayah Congko, mereka kembali diberikan izin untuk membuka persawahan oleh pihak Kerajaaan Nepo, dan sawah tersebut dinamakan sawah Congko. Orang-orang Pakkang tidak lama bermukim di wilayah Congko karena kebiasaan mereka melakukan perampokan masih dilakukan. Akibat perbuatan yang berulang-ulang oleh Arung La Bongngo memindahkan mereka jauh di atas gunung, dan sawah Congko yang mereka buat kembali diambil alih oleh pihak Kerajaan Nepo. Toponim sawah Congko kini masih bisa ditemukan, yaitu berada di wilayah administrasi Desa Siddo Kecamatan Soppeng Riaja dengan posisi astronomi lintang selatan $04^{\circ} 13^{\prime} 36.8^{\prime}$ ' bujur timur $119^{\circ} 38^{\prime} 26.6^{\prime}$ ' dengan ketinggian 19 MDPL. 


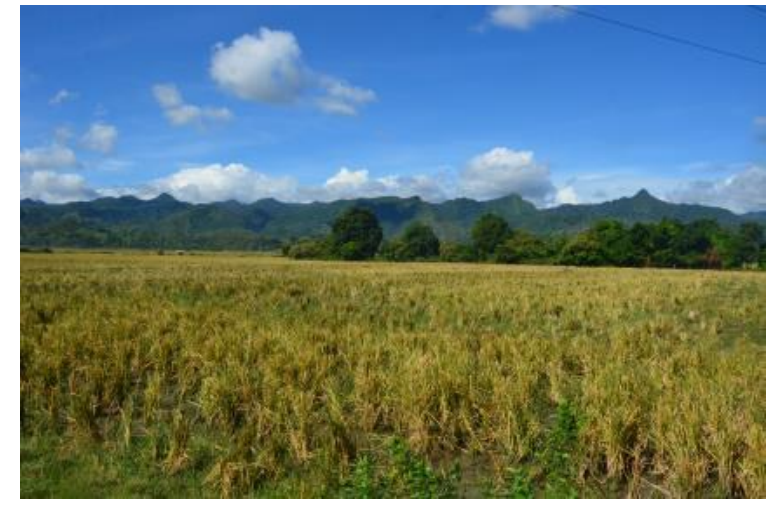

Gambar 2. Area persawahan Lapetupiona (Sumber: Dok. Balai Arkeologi Makassar, Tahun 2014)

Selain orang-orang Pakkang membuka area persawahan, tampaknya masyarakat setempat juga melakukan hal yang sama, karena pada masa-masa tersebut telah terjadi revolusi pertanian, berupa pembukaan lahan-lahan persawahan secara besarbesaran. Mereka awalnya bercocok tanam di pegunungan kemudian berpindah ke lerenglereng, dan pada masa kepemipinan Arung La Bongngo mereka membuka area persawahan besar-besar di daerah yang cukup landai dan rendah. Pembukaan area persawahan yang begitu luas dan menyebar di berbagai tempat menunjukkan bahwa corak kebudayaan agraris masyarakat Nepo sangat kuat, dan berlanjut hingga saat ini.

\section{PENUTUP}

Transformasi kepemimpinan di Kerajaan Nepo tidak merubah hakikat pembentukan Kerajaan Nepo yang berasal dari persekutuan empat puluh kampung/wanuwa. Bentuk persekutuan atau konfederasi sangat umum dilakukan di daerah Bugis pada masa lampau sebagai wujud eksistensi kampung/wanuwa dan kerajaan dalam menghadapi gejolak sosial politik internal maupun eksternal, seperti di Soppeng enam puluh wanuwa bersatu untuk menjadi Kerajaan Soppeng. Adapula persekutuan pada level kerajaan, membentuk suatu konfederasi kerajaan lebih besar seperti konfederasi Ajatappareng dan konfederasi Tellumpoccoe.
Transformasi sosial politik di Kerajaan Nepo telah melahirkan kedamaian dan kesejahteraan bagi masyarakat Nepo. Hal tersebut dapat terlihat dari berbagai sebaran temuan artefak keramik, gerabah, lesung batu, struktur pondasi bangunan masjid dan fitur area persawahan yang tersebar dan luas. Okupasi awal situs Kerajaan Nepo diperkirakan dimulai dari abad ke 16, gambaran itu diperoleh dari temuan keramik Vietnam (abad ke 16), Sawankhalok (abad ke 16), keramik Ming (abad ke 16) meski jumlahnya tidak refresentatif dibandingkan dengan abad selanjutnya. Sementara keramik periode selanjutnya yaitu keramik dinasti Qing (abad ke 17-18), keramik Swatow (abad ke 17-18) merupakan puncak kejayaan Kerajaan Nepo, kemudian pada abad ke 18-19 mengalami penurunan. Temuan fragmen keramik dan gerabah menandakan instensitas kontak masyarakat Nepo dengan masyarakat luar cukup intens, hal tersebut dapat terlihat dari temuan keramik dan gerabah di wilayah Kerajaan Nepo. Masyarakat Nepo juga telah menganut agama Islam, itu ditandai dengan ditemukannya sturktur pondasi bangunan masjid. Bangunan tersebut diperkirakan dibuat pada abad ke 19-20, akan tetapi masyarakat Nepo jauh sebelumnya sudah menganut Islam karena agama Islam sudah menyebar luas dari abad ke-16.

Corak kebudayaan masyarakat Nepo merupakan masyarakat agraris, dimana mata pokok pencaharian masyarakat Nepo bersumber dari pertanian baik di ladang maupun persawahan. Itu terlihat ketika awal mereka hidup di gunung memanfaatkan sumber daya alam disekitar mereka untuk bercocok tanam dan bertani. Mentalitas mereka sebagai masyarakat agraris juga terlihat ketika terjadi revolusi pertaninan, berupa pembukaan lahan besar-besar pada dataran rendah. Masyarakat Nepo bergotong royong membuka area persawahan Lakenynya. Cerminan sebagai masyarakat agraris juga terlihat ketika Raja La Bongngo di berikan sawah Jowa dan empat puluh 
petak sawah Parakka' sebagai fasilitas seorang raja. Begitu juga kehadiran rombongan orang-orang Pakkang yang membuka area persawahan Diapung, sawah Lapetupiyona dan sawah Congko. Corak kebudayaan agraris juga terlihat dengan ditemukannya 2 buah lesung batu untuk menumbuk biji-bijian, dan temuan lesung batu sangat erat kaitannya dengan pertanian.

\section{UCAPAN TERIMA KASIH}

Terima kasih kepada Kepala Balai Arkeologi Makassar karena telah memprogramkan kegiatan penelitian Kerajaan Nepo di Kab. Barru. Terima kasih kepada ketua tim Dra. Hj. Muheminah dan para anggota tim penelitian arkeologi. Terima kasih kepada Drs. Hasanuddin, M.Hum yang telah memberikan arahan dan bimbingan dalam pembuatan artikel ini. Terima kasih kepada Dr. Mukhlis Hadrawi yang telah menerjemahkan naskah-naskah lontara Nepo dan naskah lontara Manuba. Terima kasih kepada Karaeng Dg. Manaring yang telah melakukan klasifikasi terhadap fragmen keramik dan fragmen gerabah.

\section{DAFTAR PUSTAKA}

Asba, A. Rasyid, 2010. Kerajaan Nepo. Yogyakarta: Ombak.

Bukit, Santa, Elya dan Hasan, Himasari dan Wibowo, Sarwo, Arif, 2012. "Aplikasi Metode N.J. Habraken Pada Studi Transformasi Pemukiman Tradisional." Lingkungan Binaan Indonesia 1 (1): 51-62.

Jones, Pip, 2010. Pengantar Teori-Teori Sosial dari Teori Fungsionalisme Hingga PostModernisme. Edited by Alih Bahasa Achmad Fedyani Saifuddin. Jakarta: Yayasan Pustaka Obor Indoensia.

Makmur dan Hadrawi, Muhlis, 2016. "Otoritas Wanuwa : Kedudukan Sosial-Politik WanuwaWanuwa Hingga Terbentuknya Kerajaan Soppeng." In Lembah Walennae Lingkung Purba dan Jejak Arkeologi Peradaban Soppeng, 161-66. Yogyakarta: Ombak.

Muhaeminah dan Makmur, 2015. "Masa Awal Hingga Berkembangnya Kerajaan Ajatappareng (Abad Ke-14 - 18)." Purbawidya 4 (2): 125-35.

Muhaeminah, dkk., 2014. "Laporan Penelitian Tinggalan Arkeologi di Wilayah Kerajaan Nepo.” Makassar: Balai Arkeologi Makassar.

Pelras, Christian, 2006. Manusia Bugis. Jakarta: Nalar bekerja sama dengan Forum JakartaParis, EFEO.

Simanjuntak, Truman, dkk., 2008. Metode Penelitian Arkeologi. Jakarta: Pusat Penelitian dan Pengembangan Arkeologi Nasional.

Syani, Abdul, 1995. Sosiologi Dan Perubahan Masyarakat. Bandung: Pustaka Jaya.

Zaeny, A., 2005. “Transformasi Sosial dan Gerakan Islam di Indonesia.” Pengembangan Masyarakat Islam 1 (2): 153-65.

Zid, Muhammad dan Sjaf, Sofjan, 2009. "Sejarah Perkembangan Desa Bugis - Makassar Sulawesi Selatan." Sejarah Lontar 6 (2): 38-53. 